\title{
A customized protocol to assess bone quality in the metacarpal head, metacarpal shaft and distal radius: a high resolution peripheral quantitative computed tomography precision study
}

Lynne Feehan ${ }^{1,45^{*}}$, Helen Buie ${ }^{2}$ Linda $\mathrm{Li}^{1,4}$ and Heather McKay ${ }^{3,5}$

\begin{abstract}
Background: High Resolution-Peripheral Quantitative Computed Tomography (HR-pQCT) is an emerging technology for evaluation of bone quality in Rheumatoid Arthritis (RA). However, there are limitations with standard HR-pQCT imaging protocols for examination of regions of bone commonly affected in RA. We developed a customized protocol for evaluation of volumetric bone mineral density (VBMD) and microstructure at the metacarpal head (MH), metacarpal shaft (MS) and ultra-ultra-distal (UUD) radius; three sites commonly affected in RA. The purpose was to evaluate short-term measurement precision for bone density and microstructure at these sites.

Methods: 12 non-RA participants, individuals likely to have no pre-existing bone damage, consented to participate [8 females, aged 23 to 71 y [median (IQR): 44 (28) y]. The custom protocol includes more comfortable/stable positioning and adapted cortical segmentation and direct transformation analysis methods. Dominant arm MH, MS and UUD radius scans were completed on day one; repeated twice (with repositioning) three to seven days later. Short-term precision for repeated measures was explored using intraclass correlational coefficient (ICC), mean coefficient of variation (CV\%), root mean square coefficient of variation (RMSCV\%) and least significant change (LSC\%95).

Results: Bone density and microstructure precision was excellent: ICCs varied from 0.88 ( $\mathrm{MH}_{2}$ trabecular number) to .99 $\left(\mathrm{MS}_{3}\right.$ polar moment of inertia); $\mathrm{CV} \%$ varied from < $1\left(\mathrm{MS}_{2} \mathrm{VBMD}\right)$ to $6\left(\mathrm{MS}_{3}\right.$ marrow space diameter); RMSCV\% varied from < 1 ( $\mathrm{MH}_{2}$ full bone vBMD) to $7\left(\mathrm{MS}_{3}\right.$ marrow space diameter); and $\mathrm{LSC} \%$ 95varied from 2 ( $\mathrm{MS}_{2}$ full bone vBMD to $21\left(\mathrm{MS}_{3}\right.$ marrow space diameter). Cortical porosity measures were the exception; RMSCV\% varying from $19\left(\mathrm{MS}_{3}\right)$ to 42 (UUD). No scans were stopped for discomfort. 5\% (5/104) were repeated due to motion during imaging. 8\% (8/104) of final images had motion artifact graded $>3$ on 5 point scale.

Conclusion: In our facility, this custom protocol extends the potential for in vivo HR-pQCT imaging to assess, with high precision, regional differences in bone quality at three sites commonly affected in RA. Our methods are easy to adopt and we recommend other users of HR-pQCT consider this protocol for further evaluations of its precision and feasibility in their imaging facilities.
\end{abstract}

Keywords: HR-pQCT, Bone microstructure, Volumetric bone mineral density, Precision, Metacarpal head, Metacarpal shaft, Ultra-ultra-distal radius, Early rheumatoid arthritis

\footnotetext{
* Correspondence: lynne.feehan@gmail.com

'Department of Physical Therapy, Faculty of Medicine, University of British

Columbia (UBC), Vancouver, BC, Canada

${ }^{4}$ Arthritis Research Centre of Canada, Richmond, BC, Canada

Full list of author information is available at the end of the article
} 


\section{Background}

Despite marked improvements in the clinical management of systemic inflammatory joint-disease in early rheumatoid arthritis (RA), people with RA remain at risk for developing underlying systemic inflammatory mediated bone-changes [1-4]. Changes can include progressive periarticular bone thinning (osteopenia) and development of resorptive bone lesions (erosions) [5,6]. Periarticular bone damage, most commonly seen in the bone near the metacarpal phalangeal and wrist joints, can contribute to the development of hand deformities and profound functional limitations in people living with RA [6,7]. Additionally, systemic extra-articular inflammatory bone changes contribute to a two-fold increase in fracture risk with aging in people living with RA [8-11].

Currently, radiography and several clinical imaging systems, such as magnetic resonance imaging (MRI), computed tomography (CT), ultrasonography (US), dualenergy X-ray absorptiometry (DXA) and digital X-ray radiogrammetry (DXR) are used clinically to monitor bone changes in RA [12-17]. While these tools are useful for capturing later macro-structural joint and bone damage that occurs in RA, their abilities to identify the earlier bone microstructural bone changes are poor. Thus, there is an urgent need for new imaging technologies and methods to be developed that can reliably identify and characterize these early changes before permanent macro structural bone damage occurs. This is especially important given that early microstructural changes are potentially modifiable if they are reliably identified and treated early.

High Resolution Peripheral Quantitative CT (HR-pQCT; SCANCO Medical AG, Brüttisellen, Switzerland) is a promising imaging technology capable of imaging fine bone internal 'micro' detail at a resolution similar to the thickness of a human hair (75 to 100 microns) [18]. Thus, HR-pQCT imaging is a promising tool for evaluating the changes in bone quality that accompany RA. However, research that uses this tool in RA is limited and just emerging [19-32]. Further, it is not possible to compare and synthesize findings from studies in RA that used HR pQCT as image location, acquisition and evaluation procedures are not standardized and vary widely [33].

There are a number of possibilities for these inconsistencies with the primary reason related to applying standard protocols developed specifically for one region of interest (ROI) to another ROI without consideration of the technical limitations for doing this. Secondly, although a positioning device is available to support standard positioning of the arm, this device is not designed to position and stabilize the hand during imaging near the metacarpal phalangeal or wrist joint regions. Thirdly, standard semi-automated image evaluation protocols cannot reliably separate (segment) cortical and trabecular bone compartments in the periarticular metacarpal head and very distal radius bone regions that have very thin cortical shells.
This is notable as these regions are commonly affected in inflammatory arthritis [34]. Finally, standard image evaluation protocols were not designed to evaluate regions that are comprised primarily of compact lamellar cortical bone such as found in the extra-articular metacarpal mid-shaft region which is also commonly affected in inflammatory arthritis $[3,35,36]$.

Recently, HR pQCT semi-automated image analysis capabilities were advanced to allow more accurate segmentation of the cortical bone compartment $[37,38]$. This relatively new approach was developed to evaluate regions of bone with a thin cortical shell and therefore overcomes some of the limitations associated with the standard imaging protocols. In addition, direct transformation image analyses methods developed for microCT analyses ex vivo were recently adapted to evaluate cortical bone density, morphometry and porosity in vivo, using HRpQCT [38-41]. Importantly, these advances permit evaluation of several micro-structural and macro-structural bone parameters within the integral, trabecular and cortical bone compartments that could not previously be assessed using standard HR-pQCT evaluation protocol, in vivo. There is a need, however, to assess the precision of adapted semi-automated cortical compartment segmentation and adapted direct transformation image analyses methods for HR-pQCT assessment in vivo, generally and at bone sites commonly affected by RA (e.g. periarticular distal radius and metacarpal head regions and extra-articular metacarpal mid-shaft region).

Therefore, the purpose of this study was to determine the short term precision of an HR-pQCT imaging protocol, in vivo customized for the hand and distal radius. The novel features of this protocol include: 1) comfortable positioning and better stabilization of the head, trunk and upper arm, 2) standardized positioning of the hand and forearm using a custom-made positioning device, and 3) adapted semi-automated cortical segmentation and direct transformation image analyses methods that permit assessment of integral, cortical and trabecular bone macro- and microstructural morphometry and bone mineral density at the Metacarpal Head (MH), Metacarpal Shaft (MS) and the Ultra-Ultra-Distal (UUD) radius bone regions. We use the term Ultra-Ultra-Distal (UUD) radius to differentiate the more distal periarticular distal radius location examined in our study, from the standard ultra-distal radius scan location [42]. Our secondary objectives were to explore participant tolerance to the novel positioning protocol as well as rates for re-scanning due to motion during imaging and excessive image motion artifact (e.g. graded $>3$ on the manufacturer 5 point rating scale) in the final images [43].

\section{Methods}

This precision study was conducted in a medical imaging research centre setting and received academic institutional 
ethical approval from the University of British Columbia, Vancouver Canada. Community-dwelling adults were recruited from a large urban metropolitan setting. Participants received no financial remuneration for participation and provided informed consent to participate. With the exception of a physician diagnosis of inflammatory arthritis, participants were not screened for any other self-reported health (e.g. diabetes, osteoporosis) or lifestyle (e.g. smoking, alcohol consumption, physical inactivity) condition that may have affected their bone health. We specifically excluded individuals with a diagnosis of inflammatory arthritis as we were not be able to determine a priori if they may already have underlying macro-structural bone damage in the regions of bone we were examining. Participants were also excluded if they: 1) had any physical condition that would prevent them from sitting motionless with their arm in the scanner supported by a positioning device for up to 6 minutes, 2) had metal or surgical implants in the hand or forearm of interest, 3) were pregnant or possibly pregnant, 4) had sustained a fracture in their dominant arm hand or forearm in the previous 12 months, and 5) were unable to read or understand the consent form.

Prior to scanning we assessed height $(\mathrm{cm})$ using a wall mounted stadiometer (SECA corp. Chino, CA) and weight $(\mathrm{kg})$ using a medical grade digital floor scale (Tanita Corporation of America, Inc. Arlington Heights, Ill) using standard techniques. We derived body mass index (BMI) as wt $/ \mathrm{ht}^{2}\left(\mathrm{~kg} / \mathrm{m}^{2}\right)$ [44]. Following these anthropometric measures, the hand and forearm were positioned in a custom-made positioning device made of rigid thermoplastic splinting material. The forearm was aligned parallel to the long axis of the splint and the metacarpal phalangeal joints positioned in 0 degrees of flexion. The splint-supported hand and forearm were then positioned within a holder that was modified from manufacturer specifications to suit the hand (Scanco Medical AG, Switzerland). The hand and forearm were then stabilized with additional strapping (Figure 1A). Participants were positioned to face the imaging system. Pillows were placed behind participants' hips and in front of them so that the participant could lean forward and rest on the pillows with their opposite arm, upper body and head comfortably supported. The holder, with the arm correctly positioned within it, was then placed inside the HR pQCT unit for scan acquisition (Figure 1B).

A single trained operator (author LF) performed all scans using standard in vivo imaging parameters $(82 \mu \mathrm{m}$ nominal isotropic resolution, $60 \mathrm{kV}_{\mathrm{p}}$ effective energy, $900 \mu \mathrm{A}$ current, and $100 \mathrm{~ms}$ integration time). The training involved a rigorous and standardized training protocol developed by the facility for the safe operation of the scanner. Manufacturer specifications for the scanner define that for every 110 slices acquired the measurement time is 2.8 minutes with an effective dose of $3 \mu \mathrm{Sv}$ at distal extremity sites. This estimate of effective dose is based on a weighted computed tomography dose index (CTDIw) of $6.1 \mathrm{mGy}$ and a local dose of $3.2 \mathrm{mGy}$ using standard HR-pQCT in vivo image acquisition parameters [45]. A trained operator also performed daily density calibrations and weekly geometry calibrations of the HR-pQCT imaging system using the manufacturer's calibration phantom.

Three scans of the dominant arm were completed in series during a single scanning session. The ROIs included the metacarpal head (MH), metacarpal mid-shaft (MS) and ultra-ultra-distal (UUD) radius sites. To assess short-term precision with repositioning, we acquired two additional series of three scans with repositioning between each series. The additional two series were completed during a single scanning session, three to seven days after the initial scans.

Prior to each scan, we performed a $150 \mathrm{~mm}$ length scout view of the hand and distal forearm which is the maximum available length for a scout view. The reference line for the radius scan was located at the medial edge of the distal radius; the scan region was $1 \mathrm{~mm}$ proximal to this reference line and extended $9.02 \mathrm{~mm}$ (110 slices) proximally. For the metacarpal head scan, the reference line was the tip of the most distal second or third metacarpal head; the scan started $2 \mathrm{~mm}$ distal to this reference line and extended $18.04 \mathrm{~mm}$ (220 slices) proximally. For the metacarpal shaft scan, the reference line was half $(50 \%)$ the total length of the metacarpal shaft assessed on the scout view. The metacarpal shaft scan region of interest extended from $4.5 \mathrm{~mm}$ distal to the reference line to $9.02 \mathrm{~mm}$ (110 slices) proximal to the reference line (Figure $2 \mathrm{~A}, \mathrm{~B}, \mathrm{C}$ ).

The operator visually assessed all images for motion artifact at the completion of the three-scan series. If motion artifact was apparent in only one image the operator repeated the scan. If there was motion artifact in two or more of the scans across the series, the operator repeated the scan at one site only. Our image order of priority was the distal radius followed by the metacarpal head.

Images were then independently analysed by 1 of 2 trained and experienced operators, one of whom was the same person as the image acquisition operator in this study (first author LF), the other a study research assistance. Before conducting any image analysis in this study, each operator was required to obtain an intra-rater reliability coefficient (Pearson $\mathrm{R}$ ) of $\geq 0.90$ for measures of UUD trabecular bone fraction from at least 10 images assessed twice by the same operator within 7 to 10 days [46].

Prior to analysis, each image was graded visually for motion artifact using the 5-point manufacture grading system [47]. We included images graded 3 or less by both operators for final data analysis [43]; any disagreement was resolved by consensus. Image analyses were conducted based on operator availability; operators did not use image 


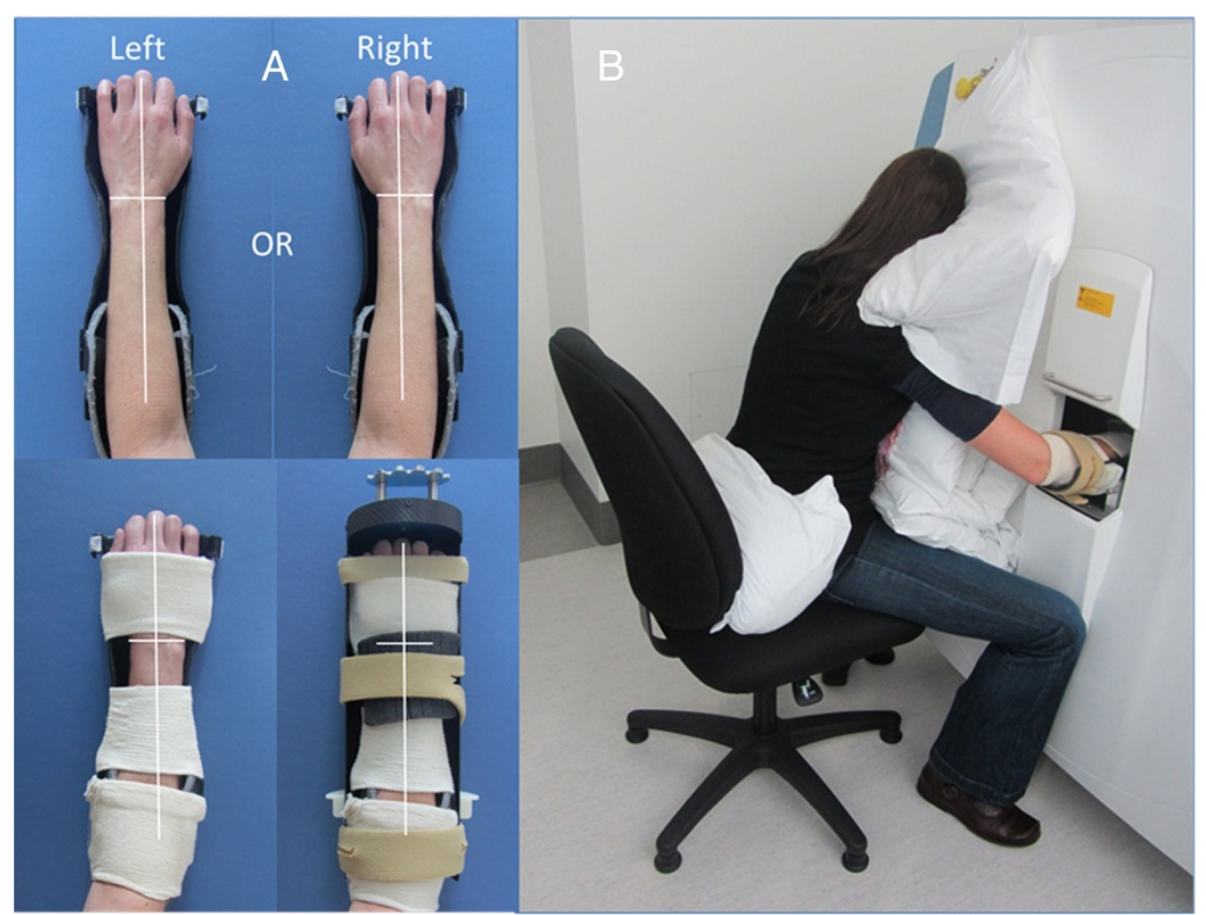

Figure 1 Custom image acquisition positioning. A) Shows the standardized positioning of the hand and forearm (left or right) in a custom-made insert (top) with additional stabilization and placement in a modified manufacturer ex-vivo holder (bottom). B) Shows the modified positioning for imaging with an individual seated on a chair facing scanner with their head, upper body and opposite arm resting on pillows with the hand to be scanned in the holder and positioned inside the scanner for scanning.

registration to evaluate repeated scans. Operators were blinded to previous image analyses data; we allowed at least 10 days between image analyses of a repeated scan in any individual by the same operator. Both operators assessed the same numbers of scan images.

Using the manufacturer evaluation software (V 6.0), the operator analyzed five sub-regions of interest [1 - UUD radius (110 slices); 2 - MH2 \& MH3 (110 slices); 2 - MS2 and MS3 (110 slices)] (Figure 2, A,B,C). They performed semi-automated contouring of the periosteal bone surface and segmented bone from surrounding soft tissue using standard manufacturer evaluation script protocols [48]. The operator extracted cortical and trabecular regions using the semi-automated segmentation method [37,38], but applied a modified boundary condition for analysis of the metacarpal head.

Following initial segmentation, the operator made minor adjustments to endosteal and periosteal contours as needed [39]. This step included a visual inspection of the computer generated lines for delineation of the cortical region segmentation in all slices, making minor manual corrections to any deviations from accurate periosteal or endosteal surface delineation (Figure 2, D,E,F). Manual correction at this step was rarely indicated; usually only required for the correction of the endosteal edge delineation in a limited number of slices in any image.
The most common reason for the need for any manual correction was in instances when there were very larger intra-cortical pores or large bi-cortical breaks created by vascular channels. These manual adjustment procedures have been described in further detail by Burghardt et al., [38].

The operator then ran a series of evaluation scripts using the manufacturer evaluation software for assessment of the full, cortical and trabecular bone regions using direct transformation image analyses scripts adapted from standard microCT evaluation scripts recently developed for cortical bone and described in more detail by Nishiyama KK et al. [40], and Liu XS et al., [41]. These adopted direct transformation evaluation scripts for HR-pQCT are now included in current upgrades of manufacturer evaluation software.

For the periarticular UUD Radius, $\mathrm{MH} 2$ and $\mathrm{MH} 3$ regions we examined apparent volumetric bone mineral density (vBMD) for the full $\left(v B M D_{\text {full }}-\mathrm{mgHA} / \mathrm{cm}^{3}\right)$, cortical $\left(\mathrm{vBMD}_{\text {Cort }}-\mathrm{mgHA} / \mathrm{cm}^{3}\right)$ and trabecular $\left(\mathrm{vBMD}_{\mathrm{Trab}}-\mathrm{mgHA} / \mathrm{cm}^{3}\right)$ bone regions. We also examined selected microstructural morphometric bone parameters, including:

- Cortical bone: thickness (CtTh - $\mathrm{mm}$ ) and porosity (CtPo - \%). 


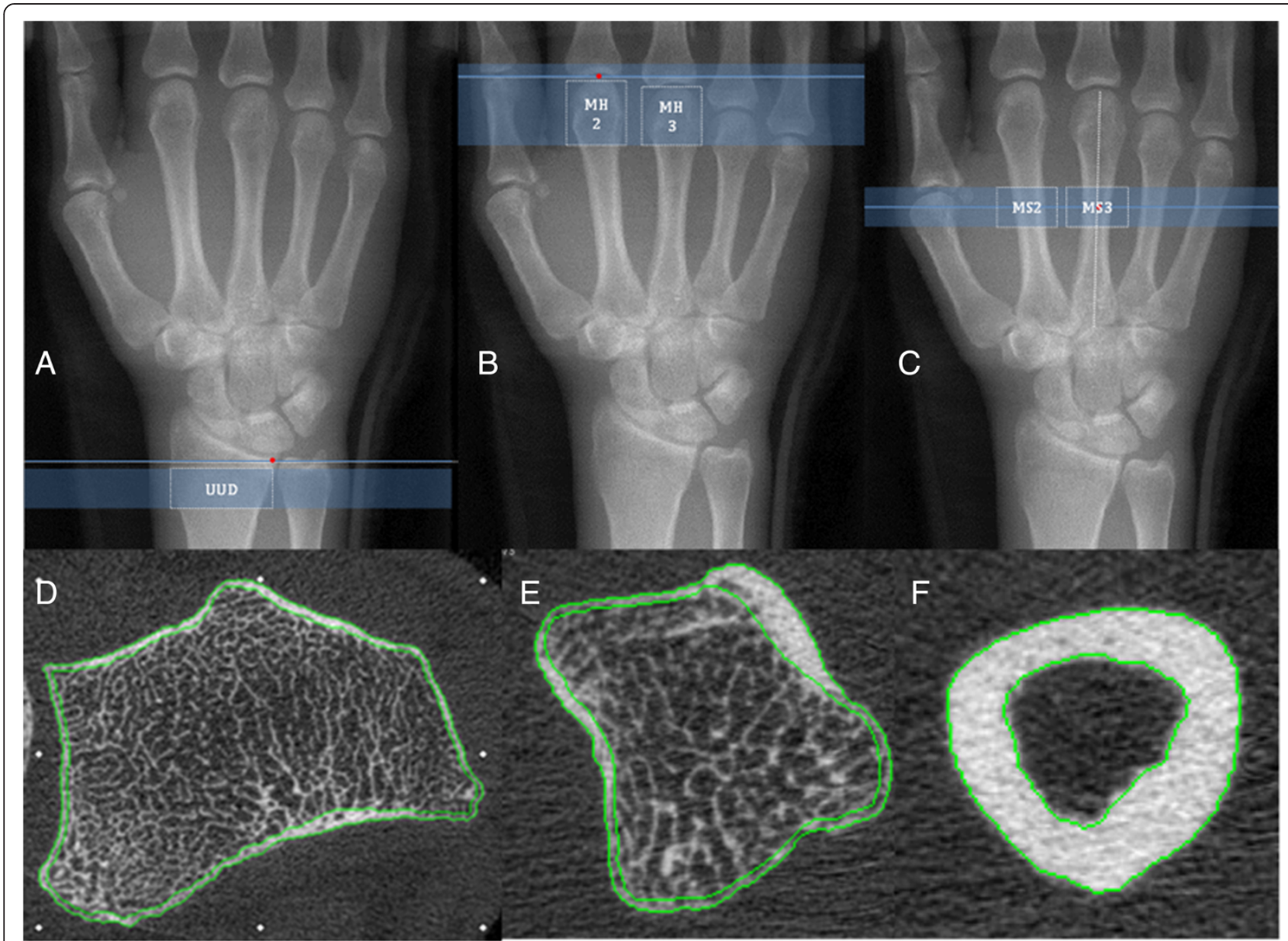

Figure 2 Scan locations and cortical segmentation. Top Row $(\mathbf{A}, \mathbf{B}, \mathbf{C})$ shows the reference line, scan location and Region of Interest (ROI) analyses overlaid on a $150 \mathrm{~mm}$ scout view for the Ultra-Ultra-Distal Radius (A), Metacarpal Head (B) and Metacarpal Shaft (C) scans. Bottom Row (D,E,F) shows examples of semi-automated cortical compartment segmentation in one HR-pQCT slice for the UUD radius (D), Metacarpal Head (E) and Metacarpal shaft (F) ROls.

- Trabecular bone: volume fraction (BV/TV $\left.\mathrm{Trab}_{\mathrm{t}} \%\right)$, number $(\mathrm{TbN}-1 / \mathrm{mm})$, thickness (TbTh - mm) and separation $(\mathrm{TbSp}-\mathrm{mm})$.

At the extra-articular MS2 and MS3 mid-shaft sites we examined full and cortical bone apparent volumetric BMD $\left(\mathrm{vBMD}_{\text {full }} \& \mathrm{vBMD}_{\text {cort }}-\mathrm{mgHA} / \mathrm{cm}^{3}\right)$, as well as, cortical bone material bone mineral density $\left(\mathrm{vTMD}_{\text {cort }}-\mathrm{mgHA} / \mathrm{cm}^{3}\right)$. In addition we examined the following selected micro- and macro-structural morphometric parameters:

- Full bone: volume $\left(\mathrm{BV}_{\text {full }}-\mathrm{mm}^{3}\right)$, volume fraction (BV/TV full - \%), section modulus - major direction $\left(\mathrm{SM}_{\text {full }}-\mathrm{mm}^{3}\right)$, polar moment of inertia $\left(\mathrm{pMOI}_{\text {full }}-\mathrm{mm}^{4}\right)$, and marrow space diameter (MSdia - mm).

- Cortical bone: thickness (CtTh - mm), porosity (CtPo - \%), volume $\left(\mathrm{BV}_{\text {cort }}-\mathrm{mm}^{3}\right)$, volume fraction
$\left(\mathrm{BV} / \mathrm{TV}_{\text {cort }}-\%\right)$, section modulus - major direction $\left(\mathrm{SM}_{\text {cort }}-\mathrm{mm}^{3}\right)$, polar moment of inertia $\left(\mathrm{pMOI}_{\text {cort }}-\mathrm{mm}^{4}\right)$.

Direct transformation evaluation methods applied to images acquired using HR-pQCT, in vivo tend to overestimate some trabecular bone outcomes (TbTh, TbSp and $\mathrm{BV} / \mathrm{TV}_{\text {trab) }}[49,50]$. Therefore, the standard manufacturer HR-pQCT evaluation script applies a correction factor to these parameters to adjust for known differences. We also applied this correction factor to variables acquired at the UUD Radius, $\mathrm{MH} 2$ and $\mathrm{MH} 3$ sites so as to directly compare our data with values acquired using standard image evaluation methods at other bone regions [41]. Trabecular bone volume fraction $\left(\mathrm{BV} / \mathrm{TV}_{\text {trab s }}\right)$ was derived using a standard approach [trabecular bone apparent volumetric bone mineral density $\left(\mathrm{vBMD}_{\text {trab }}\right)$ divided by $\left.\left.1200 \mathrm{mg} / \mathrm{cm}^{3}\right)\right]$. Trabecular thickness $\left(\mathrm{TbTh}_{\mathrm{s}}\right)$ and trabecular separation $\left(\mathrm{TbSp}_{\mathrm{s}}\right)$ were derived using a standard 
approach; $\mathrm{BV} / \mathrm{TV}_{\mathrm{s}}$ and $1-\mathrm{BV} / \mathrm{TV}_{\mathrm{s}}$ divided by $\mathrm{TbN}$, respectively. Standard evaluation of HR-pQCT images uses direct transformation methods to determine trabecular number $(\mathrm{TbN})$ and full bone and trabecular bone apparent volumetric bone mineral density $\left(\mathrm{vBMD}_{\text {full }}\right.$ and $\left.\mathrm{vBMD}_{\text {trab }}\right)$. Therefore we did not apply conversion factors to these variables.

We assessed short-term precision of repeated measures with repositioning using intraclass correlational coefficient (ICC), mean coefficient of variation (CV\%), root mean square coefficient of variation (RMSCV\%) and least significant change (LSC\% $\left.{ }_{95}\right)$ [51]. Participant tolerance to the imaging protocol and rates of excessive image motion artifact were assessed by percentage of scan reacquisition due to discomfort or motion during imaging and percentage of final images graded as higher than 3 on a 5 point scale respectively $[47,52,53]$.

\section{Results}

12 individuals (8 females) participated. Participants were aged 23 to 71 years [Median (IQR): 44 (28) y]. Participants' BMI varied from 19 to $30 \mathrm{~kg} / \mathrm{m}^{2}$ [Median (IQR): 24 (4.5) $\mathrm{kg} / \mathrm{m}^{2}$ ] (Table 1). Of the 108 potential scans, 104 were completed (96\%). The four scans not completed included $2 \mathrm{MH}$ and MS scans not done in one participant during the second session as the participant was not feeling well and did not want to re-schedule. Of the 104 completed scans, none needed to be stopped due to discomfort during the scanning session. Whereas, 5 of the 104 completed scans $(5 \% ; 3 \mathrm{MH}, 1 \mathrm{UUD}, 1 \mathrm{MS})$ were repeated at the time of acquisition due to motion artifact detected by the operator at the time of imaging. Of 104 final images acquired, we excluded 8 ( $8 \%$; 3 UUD, $3 \mathrm{MH}, 2 \mathrm{MS}$ ) from the final image analyses due to motion artifact graded higher than 3 . Notably, of the 8 images excluded from the final analyses, 4 images (1 UUD, $2 \mathrm{MH}, 1 \mathrm{MS}$ ) were from the same participant (71 y.o. male) who had a resting hand tremor that was not detected at the time of screening $[43,53,54]$. This left 96 images available for final analyses.

For the final repeated measures analyses we were able to analyze imaging data at the UUD region for 11 of the 12 participants as data from one participant was excluded due to motion artifact in 2 of the 3 UUD images. For the metacarpal head and shaft regions, we analyzed data from 10 of the 12 participants. One participant's MH and MS repeated measures data was missing because these scans were not completed during the follow up session. As well, one other participant's $\mathrm{MH}$ and another participant's MS data were excluded due to motion artifact in 2 of 3 images.

Precision for measures of volumetric BMD and macro- and microstructural bone morphometry was very high at all five sub-ROIs $[51,55]$. ICCs varied from 0.88 (MH2 - TbN) to .99 (MS3 - $\mathrm{pMOI}_{\text {cort }}$ ). CV\% varied from $<1\left(\mathrm{MS} 2-\mathrm{vBMD}_{\text {cort }}\right)$ to $6\left(\mathrm{MS} 3-\mathrm{Ms}_{\mathrm{dia}}\right)$. RMSCV\% varied from $<1\left(\mathrm{MH} 2-\mathrm{vBMD}_{\text {full }}\right)$ to $7\left(\mathrm{MS} 3-\mathrm{MS}_{\mathrm{dia}}\right)$ and $\mathrm{LSC}_{95}$ varied from $2\left(\mathrm{MS} 2-\mathrm{vTMD}_{\text {cort }}\right)$ to 21 $\left(\mathrm{MS} 2-\mathrm{MS}_{\mathrm{dia}}\right)$. The exceptions were the poor measures we report for cortical porosity at all three measurement sites [RMSCV\% varying from 19 (MS3) to 42 (UUD)] (Tables 2,3,4).

Across all regions, vBMD measurement precision was better than precision for measures of microstructural morphology; RMSCV\% for ${ }_{\mathrm{V}} \mathrm{BMD}$ varied from $<1$ to 4 compared with microstructural morphology which varied from $<1$ to 7 . At the periarticular UUD radius and the second and third $\mathrm{MH}$ sites, precision was better for trabecular bone microstructural morphology (RMSCV\%: < 1 to 4 ) compared to measures of cortical thickness (RMSCV\%: 3 to 7). At the extra-articular second and third MS sites the precision for measures of full and cortical bone density as well as macro- and microstructural morphometry (RMSCV\%: < 1 to 3 ) was better than precision for measures of marrow space diameter (RMSCV\%: 5 to 7) (Tables 2,3,4).

\section{Discussion}

This study extends the literature that uses in HR pQCT to examine "bone quality" in vivo in a novel way using customized image acquisition and analyses protocols to assess bone parameters in the distal forearm and hand. We deliberately focus upon these regions of interest given they are sites where trabecular and cortical bone is commonly affected in individuals living with RA. We demonstrated that our custom HR-pQCT imaging protocol, in vivo is a precise means to assess integral, cortical and trabecular bone density and macro- and microstructure (with the exception of cortical porosity) at the MH, MS and UUD radius in our imaging facility.

Some distinguishing features of our custom image acquisition methods are; 1 ) more comfortable and stable positioning of the head, trunk and arm during imaging,

Table 1 Participant demographics

\begin{tabular}{llll}
\hline & Females $(\mathbf{n}=\mathbf{8})$ & Males $(\mathbf{n}=\mathbf{4})$ & All $(\mathbf{n}=\mathbf{1 2})$ \\
\hline Age (years): median (IQR); min-max & $44(\mathrm{n} / \mathrm{a}) ; 23-62$ & $45(\mathrm{n} / \mathrm{a}) ; 23-71$ & $44(28) ; 23-71$ \\
Height $(\mathrm{cm})$ : median (IQR); min-max & $165(\mathrm{n} / \mathrm{a}) ; 158-174$ & $185(\mathrm{n} / \mathrm{a}) ; 175-195$ & $173(18.5) ; 158-195$ \\
Weight $(\mathrm{kg})$ : median (IQR); min-max & $64(\mathrm{n} / \mathrm{a}) ; 63-76$ & $77(\mathrm{n} / \mathrm{a}) ; 64-94$ & $65(12.5) ; 55-94$ \\
BMI $\left(\mathrm{kg} / \mathrm{m}^{2}\right)$ : median (IQR); min-max & $24(\mathrm{n} / \mathrm{a}) ; 19-30$ & $21(\mathrm{n} / \mathrm{a}) ; 19-24$ & $24(4.5) ; 19-30$ \\
\hline
\end{tabular}


Table 2 Summary of the results for Ultra-Ultra-Distal (UUD) radius region of interest $(n=11)$

\begin{tabular}{|c|c|c|c|c|c|c|c|c|}
\hline \multicolumn{4}{|c|}{ Variables } & \multirow{2}{*}{$\begin{array}{c}\text { Mean (SD) } \\
362(102)\end{array}$} & \multirow{2}{*}{$\begin{array}{c}\text { ICC } \\
\mathbf{( 0 . 0 0 0 - 1 . 0 0 0 )} \\
0.986\end{array}$} & \multirow{2}{*}{$\begin{array}{c}\begin{array}{c}\text { Mean coefficient } \\
\text { of variation (CV\%) }\end{array} \\
2.3\end{array}$} & \multirow{2}{*}{$\begin{array}{c}\text { Root mean square } \\
\text { CV (RMSCV\%) }\end{array}$} & \multirow{2}{*}{  } \\
\hline Density & Full Bone (mgHA/cm3) & vBMD full & $D \& S$ & & & & & \\
\hline & $\begin{array}{l}\text { Cortical density } \\
(\mathrm{mgHA} / \mathrm{cm} 3)\end{array}$ & $\mathrm{VBMD}_{\text {cort }}$ & D & 944 (189) & 0.962 & 3.5 & 3.7 & 10.4 \\
\hline & $\begin{array}{l}\text { Trabecular density } \\
(\mathrm{mgHA} / \mathrm{cm} 3)\end{array}$ & $\mathrm{vBMD}_{\text {trab }}$ & $D \& S$ & $272(69)$ & 0.993 & 1.3 & 1.6 & 4.5 \\
\hline \multirow{2}{*}{$\begin{array}{l}\text { Cortical } \\
\text { bone }\end{array}$} & Thickness (mm) & CtTh & D & $0.59(0.20)$ & 0.959 & 5.9 & 7.3 & 20.2 \\
\hline & Porosity (\%) & $\mathrm{CtPo}$ & D & $1.3(0.7)$ & 0.320 & 34.0 & 41.7 & 115.6 \\
\hline \multirow{7}{*}{$\begin{array}{l}\text { Trabecular } \\
\text { bone }\end{array}$} & Bone volume & $\mathrm{BV} / \mathrm{TV}$ trab & $\mathrm{D}$ & $37(7)$ & 0.990 & 1.7 & 2.0 & 5.7 \\
\hline & & $\mathrm{BV} / \mathrm{TV}$ trabs & S & $23(6)$ & & & & \\
\hline & Number (1/mm) & $\mathrm{TbN}$ & $D \& S$ & $2.4(0.3)$ & 0.908 & 3.1 & 4.3 & 12.1 \\
\hline & Thickness (mm) & TbTh & $\mathrm{D}$ & $0.22(0.02)$ & 0.956 & 0.79 & 4.5 & 12.6 \\
\hline & & $\mathrm{TbTh}_{\mathrm{s}}$ & S & $0.10(0.01)$ & & & & \\
\hline & Separation (mm) & TbSp & $\mathrm{D}$ & $0.38(0.07)$ & 0.932 & 3.4 & 1.1 & 3.0 \\
\hline & & $\mathrm{TbSp}_{\mathrm{s}}$ & S & $0.34(0.07)$ & & & & \\
\hline
\end{tabular}

$\mathrm{D}=$ Direct Transformation Method; $\mathrm{S}($ Grey fill $)=$ Derived Standard Clinical Equivalent.

and 2) standardized positioning and stabilization of the metacarpal phalangeal and wrist joints in a custom-made positioning device. These are important advantages as better stabilization during imaging reduces the potential for participant motion during scanning as well as the degree of motion artifact in final images. Notably, the percentage of scans repeated due to motion identified at the time of scanning (scan re-acquisition: $5 \%$ vs. $29 \%$ ) as well as percentage of images graded higher than 3 (Poor Image Quality: 8\% vs. 20\%) was markedly lower than previously reported values for these parameters using the standard HR-pQCT distal radius protocol [47,54]. Moreover, standardized positioning allows more consistent visual land-marking to locate the scan ROI. This negates the need for the operator to use computer assisted image registration methods to evaluate repeated images of the same bone regions in either short term follow up or longer term prospective studies [54].

Using adapted semi-automated cortical segmentation methods ensured the operator was able to reliably extract the cortical bone compartment in all the regions of bone we examined. This is an important finding, especially given the challenges presented by very thin and highly porous cortical shells in the periarticular distal radius and metacarpal head regions (Figure 3). Reliable and

Table 3 Summary of results for the Metacarpal Head $(\mathrm{MH}) 2 \& 3$ regions of interest $(n=10)$

\begin{tabular}{|c|c|c|c|c|c|c|c|c|c|c|c|c|c|}
\hline \multicolumn{4}{|c|}{ Variables } & \multicolumn{2}{|c|}{ Mean (SD) } & \multicolumn{2}{|c|}{ ICC (0.000-1.000) } & \multicolumn{2}{|c|}{$\begin{array}{c}\text { Mean } \\
\text { coefficient } \\
\text { of variation } \\
\text { (CV\%) } \\
\end{array}$} & \multicolumn{2}{|c|}{$\begin{array}{l}\text { Root mean } \\
\text { square CV } \\
\text { (RMSCV\%) }\end{array}$} & \multicolumn{2}{|c|}{$\begin{array}{c}\text { Least } \\
\text { significant } \\
\text { change\% } \\
\text { (LSC\%95) }\end{array}$} \\
\hline & & & & MH3 & $\mathrm{MH} 2$ & MH3 & MH2 & MH3 & $\mathrm{MH} 2$ & MH3 & $\mathrm{MH} 2$ & MH3 & $\mathrm{MH} 2$ \\
\hline \multirow{3}{*}{$\begin{array}{c}\text { Density } \\
\text { (Apparent) }\end{array}$} & Full bone (mgHA/cm3) & $v B M D_{\text {full }}$ & $D \& S$ & $438(89)$ & $434(82)$ & 0.997 & 0.998 & 0.83 & 0.57 & 1.0 & 0.78 & 2.8 & 2.2 \\
\hline & Cortical (mgHA/cm3) & $\mathrm{vBMD}_{\text {cort }}$ & D & $743(106)$ & 751 (101) & 0.975 & 0.975 & 1.5 & 1.3 & 2.1 & 1.6 & 6.0 & 4.5 \\
\hline & Trabecular (mgHA/cm3) & $v_{B M D}$ trab & $D \& S$ & $387(79)$ & $378(73)$ & 0.996 & 0.997 & 0.8 & 0.7 & 1.2 & 1.0 & 3.2 & 2.9 \\
\hline \multirow[t]{2}{*}{ Cortical bone } & Thickness (mm) & CtTh & $\mathrm{D}$ & $0.39(0.07)$ & $0.39(0.06)$ & 0.933 & 0.973 & 4.8 & 1.6 & 6.17 & 2.7 & 17.1 & 7.4 \\
\hline & Porosity (\%) & CtPo & $\mathrm{D}$ & $1.2(0.7)$ & $1.2(0.4)$ & 0.153 & 0.727 & 23.2 & 17.0 & 33.2 & 22.2 & 92.1 & 61.4 \\
\hline \multirow[t]{7}{*}{ Trabecular bone } & Volume fraction (\%) & $\mathrm{BV} / \mathrm{TV}$ trab & $\mathrm{D}$ & $46(5)$ & $46(6)$ & 0.984 & 0.984 & 1.2 & 1.3 & 1.5 & 1.6 & 4.3 & 4.5 \\
\hline & & $\mathrm{BV} / \mathrm{TV}_{\text {trabs }}$ & $S$ & $26(13)$ & $26(13)$ & & & & & & & & \\
\hline & Number (1/mm) & $\mathrm{TbN}$ & $D \& S$ & $2.6(0.24)$ & $2.5(0.23)$ & 0.904 & 0.884 & 2.1 & 2.2 & 2.5 & 2.8 & 6.9 & 7.7 \\
\hline & Thickness (mm) & TbTh & $\mathrm{D}$ & $0.23(0.02)$ & $0.24(0.02)$ & 0.978 & 0.978 & 0.74 & 1.1 & 3.9 & 3.5 & 10.8 & 9.8 \\
\hline & & $\mathrm{TbTh}_{\mathrm{s}}$ & S & $0.11(0.03)$ & $0.11(0.03)$ & & & & & & & & \\
\hline & Separation (mm) & TbSp & D & $0.34(0.05)$ & $0.34(0.06)$ & 0.928 & 0.944 & 3.0 & 3.0 & 1.1 & 1.3 & 3.0 & 3.5 \\
\hline & & $\mathrm{TbSp}_{\mathrm{s}}$ & S & $0.27(0.05)$ & $0.29(0.05)$ & & & & & & & & \\
\hline
\end{tabular}


Table 4 Summary of results for Metacarpal Shaft (MS) 2 \& 3 regions of interest $(n=10)$

\begin{tabular}{|c|c|c|c|c|c|c|c|c|c|c|c|c|}
\hline \multicolumn{3}{|c|}{ Variables } & \multicolumn{2}{|c|}{ Mean (SD) } & \multicolumn{2}{|c|}{ ICC $(0.000-1.000)$} & \multicolumn{2}{|c|}{$\begin{array}{c}\text { Mean } \\
\text { coefficient } \\
\text { of variation } \\
\text { (CV\%) }\end{array}$} & \multicolumn{2}{|c|}{$\begin{array}{l}\text { Root mean } \\
\text { square CV } \\
\text { (RMSCV\%) }\end{array}$} & \multicolumn{2}{|c|}{$\begin{array}{c}\text { Least } \\
\text { significant } \\
\text { change\% } \\
\left(\text { LSC }_{95}\right)\end{array}$} \\
\hline & & & MS3 & MS2 & MS3 & MS2 & MS3 & MS2 & MS3 & MS2 & MS3 & MS2 \\
\hline \multirow[t]{2}{*}{ Density (Apparent) } & Full bone $(\mathrm{mgHA} / \mathrm{cm} 3)$ & $\mathrm{VBMD}_{\text {full }}$ & $1181(207)$ & $1230(180)$ & 0.994 & 0.981 & 0.88 & 1.8 & 1.2 & 2.9 & 3.3 & 7.9 \\
\hline & Cortical (mgHA/cm3) & vBMD cort & $1482(173)$ & $1492(172)$ & 0.993 & 0.996 & 0.83 & 0.49 & 1.0 & 0.80 & 2.8 & 2.2 \\
\hline Density (Material) & Cortical (mgHA/cm3) & vTMD $D_{\text {cort }}$ & $1568(194)$ & 1564 (199) & 0.996 & 0.997 & 0.57 & 0.66 & 0.72 & 1.0 & 2.0 & 2.8 \\
\hline \multirow[t]{5}{*}{ Cortical bone } & Thickness (mm) & CtTh & $1.8(0.37)$ & $2.0(0.34)$ & 0.989 & 0.989 & 1.5 & 1.7 & 1.9 & 1.9 & 5.3 & 5.1 \\
\hline & Porosity (\%) & CtPo & $0.29(0.31)$ & $0.31(0.22)$ & 0.790 & 0.949 & 16.7 & 29.0 & 18.8 & 36.0 & 52.2 & 99.7 \\
\hline & Volume $\left(\mathrm{mm}^{3}\right)$ & $B V_{\text {cort }}$ & $374(101)$ & $412(109)$ & 0.998 & 0.998 & 0.97 & 0.93 & 1.3 & 1.1 & 3.6 & 3.1 \\
\hline & Section modulus-major $\left(\mathrm{mm}^{3}\right)$ & $S M_{\text {cort }}$ & $55(20)$ & $61(23)$ & 0.998 & 0.997 & 1.2 & 1.4 & 1.4 & 1.7 & 3.9 & 4.9 \\
\hline & Polar moment of inertia $\left(\mathrm{mm}^{4}\right)$ & $\mathrm{pMOI}_{\text {cort }}$ & $476(234)$ & $535(256)$ & 0.999 & 0.998 & 0.87 & 1.9 & 1 & 2.0 & 2.8 & 5.6 \\
\hline \multirow[t]{5}{*}{ Full bone } & Volume $\left(\mathrm{mm}^{3}\right)$ & $B V_{\text {full }}$ & $475(120)$ & $499(126)$ & 0.997 & 0.997 & 0.77 & 0.97 & 1.0 & 1.1 & 2.8 & 3.1 \\
\hline & Volume fraction (\%) & $\mathrm{BV} / \mathrm{TV}$ full & $76(9)$ & $80(7)$ & 0.991 & 0.976 & 0.71 & 1.2 & 0.82 & 1.5 & 2.3 & 4.2 \\
\hline & Marrow space diameter (mm) & MSdia & $2.6(0.87)$ & $2.6(0.73)$ & 0.961 & 0.979 & 5.7 & 3.9 & 7.4 & 4.9 & 20.5 & 13.6 \\
\hline & Section modulus - major $\left(\mathrm{mm}^{3}\right)$ & $S M_{\text {full }}$ & $52(20)$ & $58(23)$ & 0.997 & 0.998 & 1.4 & 1.1 & 1.7 & 1.5 & 4.6 & 4.0 \\
\hline & Polar moment of inertia $\left(\mathrm{mm}^{4}\right)$ & $\mathrm{pMOl}_{\text {full }}$ & $444(232)$ & $498(254)$ & 0.998 & 0.998 & 1.3 & 1.7 & 1.6 & 1.8 & 4.3 & 5.1 \\
\hline
\end{tabular}

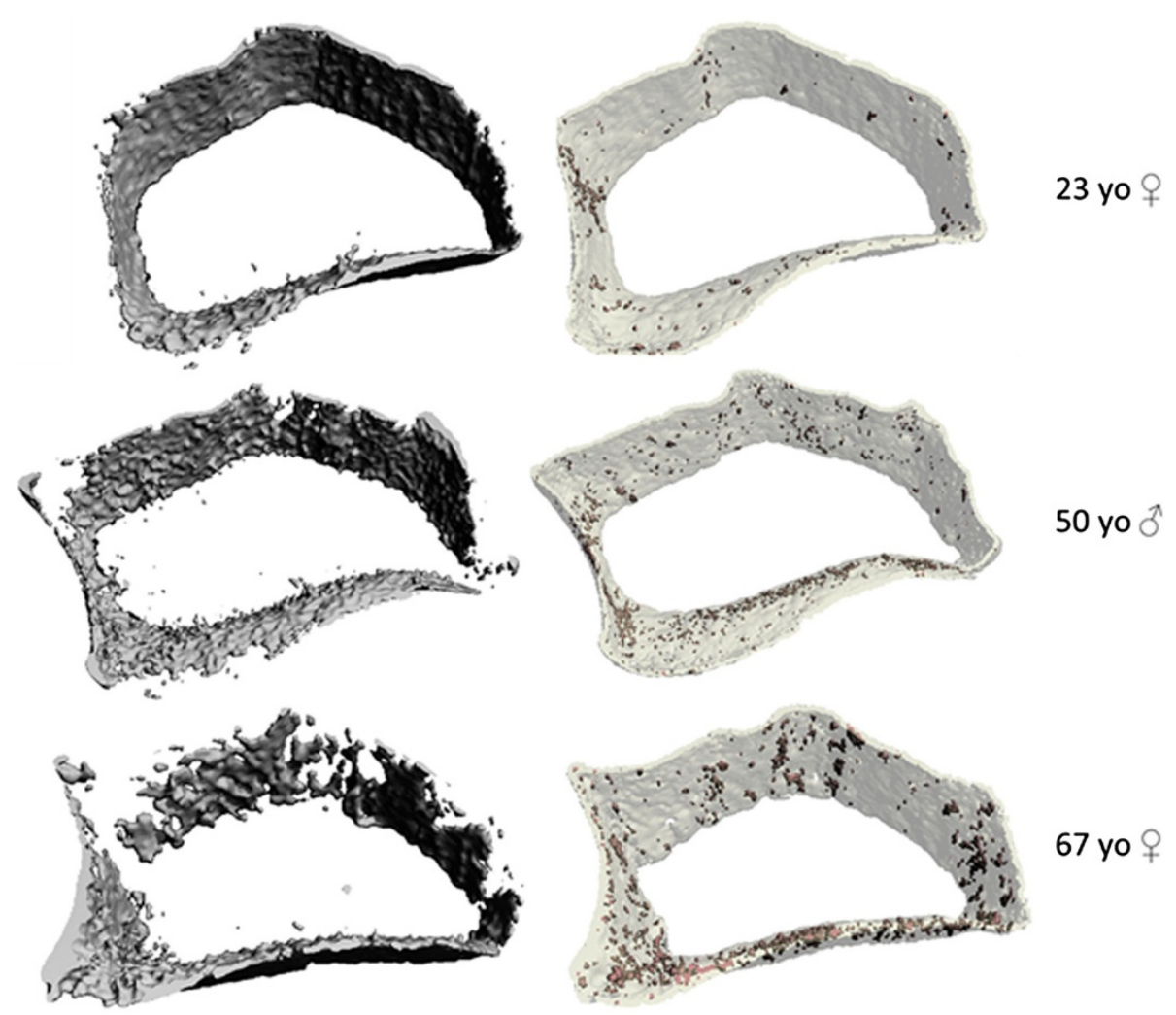

Figure 3 Cortical compartment 3-dimentional reconstructed images. 3-D reconstructed images of segmented cortical compartments from the same HR-pQCT images of the ultra-ultra-distal radius region in three participants (top row - 23 y.o. female, middle row - 50 y.o. male, bottom row - 67 y.o. female) using the standard clinical evaluation protocol (left) compared to our semi-automated cortical segmentation protocol (right). The images on the right also show shaded areas of cortical porosity identified with the adapted direct transformation cortical evaluation script. 
more accurate cortical bone segmentation methods add to the unique ability of HR-pQCT imaging, in vivo to evaluate the independent contribution of trabecular and cortical bone compartment density and microstructural parameters to integral bone strength [56-58].

We demonstrated that adapted direct transformation image analysis methods traditionally used in microCT imaging were also able to precisely assess many aspects of integral, trabecular and cortical bone density, macroand microstructure that are not currently assessed using standard HR-pQCT evaluation methods, in vivo (cortical porosity was the exception). By including derived standard evaluation equivalent values for trabecular bone volume fraction, thickness and spacing, users are also able to compare outcomes with normative or other values reported at standard distal radius and tibia scan sites [59].

Importantly, precision for bone density, macro- and microstructure at the $\mathrm{MH}, \mathrm{MS}$ and UUD radius regions we report in our imaging facility was comparable to previously reported values for distal radius and metacarpal head bone microstructure and bone mineral density measurement precision using HR pQCT [21,53]. To our knowledge, our study is the first to assess HR-pQCT's ability to precisely evaluate bone density, bone macro- and microstructure at the very distal periarticular UUD radius site, in vivo. Our findings align with estimates of HR-pQCT precision error, in vivo at the standard radius site [RMSCV\%; vBMD, < 1-2; microstructure, 1-6] and a site more proximal to the standard distal radius location [RMSCV\% $<1-2$; microstructure <1-7] $[42,60]$. As well as HR-pQCT microstructure precision $(\mathrm{CV} \%,<1-6)$ at the UUD radius site in cadaver bone ex vivo (similar to the site we assessed) [61]. This is notable as motion artifact is not an issue when assessing tissue, ex vivo.

The metacarpal mid-shaft region provides a unique opportunity to use HR-pQCT imaging to examine cortical bone density and morphometry in vivo in the shaft region of long bone that macro-structurally has a relatively thick (approximately $2 \mathrm{~mm}$ ) cortical compartment that is comprised primarily of lamellar compact cortical bone. To our knowledge, no other study has examined the precision of $\mathrm{HR} \mathrm{pQCT}$ for in vivo measures in the mid-shaft region of a long bone. It is encouraging that, with the exception of marrow space diameter and cortical porosity, that apparent and material volumetric bone mineral density, as well as, several macro- and microstructure parameters in this novel mid-shaft region can be assessed with very high precision $(\mathrm{RMSCV} \%<2)$ using $\mathrm{HR}-\mathrm{pQCT}$, in vivo. Development of novel approaches for evaluation of cortical bone quality is key given the important contribution of cortical bone to overall bone strength and fracture risk, as well as, differences in the rate and mechanisms for cortical and trabecular bone turnover with aging and many chronic diseases [57,62-65].
A few others have examined measurement precision of metacarpal head microstructure in those with RA [21,26,30,31]. Fouque-Aubert et al. [21], used standard image methods to assess HR-pQCT density and reported microstructure measurement precision in vivo at the metacarpal head in people living with RA compared with Non-RA controls. They found no notable difference in $\mathrm{vBMD}$ measurement precision between those with RA and controls $(\mathrm{CV} \%<2)$. These values align exactly with the $\mathrm{CV}$ we report for vBMD at the metacarpal head. Fouque-Aubert et al. [21], also found no differences between those with RA and controls for measurement precision of standard trabecular microstructural parameters $(\mathrm{CV}$ varied from 3 to 7\%), with the exception of trabecular separation (CV of 13\% in RA participants versus 6\% in controls). Comparably, the CV for standard and other additional microstructural parameters we examined at the metacarpal head varied from 1 to $5 \%$. As our protocol aimed to control motion artifact due to robust stabilization of the measured part, standardize positioning of the hand and wrist joints and enhance accuracy of segmentation of the very thin cortical bone compartment - these factors taken together may account for improved cortical and trabecular bone microstructure measurement precision at the metacarpal head in this study compared to the standard imaging protocols reported previously [21].

Cortical porosity is difficult to assess reliably and this held true for all regions of bone examined in our study. Relatively low precision for cortical porosity measured at the standard radius (RMSCV; 13\%) [38], and a more proximal distal radius site (RMSCV; $6+/-8 \%$ ) have been reported previously [42]. Precision for cortical porosity at the $\mathrm{MH}, \mathrm{MS}$ and UUD radius sites we examined were even poorer (RMSCV, 19 - 42\%). There are a number of factors that might explain this. First, is the current $82 \mu \mathrm{m}$ image voxel resolution of HR-pQCT, in vivo. Thus, it is difficult to resolve pore diameters smaller than this within the intracortical bone region, particularly in regions of bone with very thin cortical shells $[66,67]$. Second, on the endosteal surface of the cortical-trabecular bone interface, cortical pores are difficult to distinguish from marrow space [39]. One clear solution is enhanced image resolution in vivo. Indeed, as better image resolution continues to evolve and newer methods of cortical porosity evaluation are developed more precise methods to assess porosity in regions of thin or more compact cortical bone locations will become available [68,69].

We acknowledge that our study has limitations. This study was conducted in a small cohort of health adults in a single imaging facility, using imaging operators with extensive experience with in vivo image acquisition and analyses using HR-pQCT. As such, the precision of this custom protocol in our facility cannot be generalized to other imaging facilities that utilize HR-pQCT imaging 
that are not familiar with, or trained in, the image acquisition and analyses protocols used in this study. Further studies, ideally from multiple centres, are required to further define the precision and feasibility for this protocol. We also could not explore inter-rater reliability as none of the images in this study were evaluated by both image analyses operators. However, and notably, the effect of any measurement error associated with individual variations in image analyses was likely negligible given the high measurement precision demonstrated in this study. As well, we excluded people living with inflammatory arthritis in this precision study as we wanted to explore the utility of our custom HR-pQCT protocol for identifying and characterizing early microstructural bone changes in bone prior to permanent macro-structural damage occurring. This was an a priori decision as we were unable to determine if a person diagnosed with inflammatory arthritis may or may not already have underlying bone changes in the regions of bone commonly affected by RA. As such, our findings for measurement precision in the metacarpal head and UUD radius periarticular regions cannot be generalized to individuals living with more advanced RA where macro-structural changes from resorptive bone lesions (erosions) may already be present or where positioning may be affected by the presence of hand deformities. We also did not apply newly available cortical bone porosity image analyses procedures so we do not know if they would enhance the precision of cortical porosity measures at the $\mathrm{MH}, \mathrm{MS}$ or UUD radius $[68,69]$.

In summary, we demonstrated excellent precision for measures of bone density and many macro- and microstructural parameters at the MH, MS and UUD radius using a customized HR-pQCT protocol in our facility. The novel image acquisition protocol was well tolerated by all the participants and provided excellent stabilization of the forearm and hand during imaging resulting in a low percentage of final images with excessive motion artifact. The novel image acquisition protocol reflects a number of other practical advantages over the standard distal radius image acquisition protocol and can be easily adopted by HR-pQCT users. Additionally, the adapted semi-automatic cortical segmentation and direct transformation image evaluation methods used in this study are also available to other HR-pQCT users through the most recent manufacturer image evaluation software upgrades.

\section{Conclusion}

In our facility, this custom protocol extends the potential for using in vivo HR pQCT imaging technology to assess, with high precision, integral, trabecular and cortical bone density and microstructure at sites in the distal forearm and hand most commonly affected in rheumatoid arthritis. As such, we recommend that this customized protocol be considered by other HR-pQCT users for further evaluations of its precision and feasibility in their imaging facility.

\section{Competing interests}

The authors declare that they have no competing interests.

\section{Authors' contributions}

LF conceived the study and design, managed and participated in the image acquisition and analyses, contributed to the data analysis and interpretation and drafted all versions of the manuscript. HB was involved in the development and implementation of the adapted image analyses protocols. $\mathrm{LL}$ and $\mathrm{HM}$ contributed to the study design, interpretation of the data and editing of manuscript drafts. All authors read and approved the final manuscript.

\section{Acknowledgments}

We thank Eric Sayre, PhD. Arthritis Research Centre of Canada, Richmond, BC, Canada for his assistance with the statistical analyses.

\section{Author details}

${ }^{1}$ Department of Physical Therapy, Faculty of Medicine, University of British Columbia (UBC), Vancouver, BC, Canada. ${ }^{2}$ The Bone Imaging Laboratory, University of Calgary, Calgary, AB, Canada. ${ }^{3}$ Departments of Orthopedics and Family Medicine, Faculty of Medicine, UBC, Vancouver, BC, Canada. ${ }^{4}$ Arthritis Research Centre of Canada, Richmond, BC, Canada. ${ }^{5}$ Centre for Hip Health and Mobility, Faculty of Medicine, UBC, Vancouver, BC, Canada.

Received: 21 August 2013 Accepted: 18 December 2013

Published: 24 December 2013

\section{References}

1. Brown AK, Conaghan PG, Karim Z, Quinn MA, Ikeda K, Peterfy CG, Hensor E, Wakefield RJ, O'Connor PJ, Emery P: An explanation for the apparent dissociation between clinical remission and continued structural deterioration in rheumatoid arthritis. Arthritis Rheum 2008, 58:2958-2967.

2. Rezaei $H$, Saevarsdottir S, Forslind K, Albertsson K, Wallin H, Bratt J, Ernestam S, Geborek P, Pettersson IF, van Vollenhoven RF: In early rheumatoid arthritis, patients with a good initial response to methotrexate have excellent 2-year clinical outcomes, but radiological progression is not fully prevented: data from the methotrexate responders population in the SWEFOT trial. Ann Rheum Dis 2012, 71:186-191.

3. Rezaei H, Saevarsdottir S, Geborek P, Petersson IF, van Vollenhoven RF, Forslind $\mathrm{K}$ : Evaluation of hand bone loss by digital X-ray radiogrammetry as a complement to clinical and radiographic assessment in early rheumatoid arthritis: results from the SWEFOT trial. BMC Musculoskelet Disord 2013, 14:79.

4. Naumann L, Hermann K-GA, Huscher D, Lenz K, Burmester G-R, Backhaus M, Buttgereit F: Quantification of periarticular demineralization and synovialitis of the hand in rheumatoid arthritis patients. Osteoporos Int 2012, 23:2671-2679.

5. Vis M, Güler-Yüksel M, Lems WF: Can bone loss in rheumatoid arthritis be prevented? Osteoporos Int 2013, 24(10):2541-2553.

6. Johnsson PM, Eberhardt K: Hand deformities are important signs of disease severity in patients with early rheumatoid arthritis. Rheumatology 2009, 48:1398-1401.

7. Toyama S, Tokunaga D, Fujiwara H, Oda R, Kobashi H, Okumura H, Nakamura S, Taniguchi D, Kubo T: Rheumatoid arthritis of the hand: a five-year longitudinal analysis of clinical and radiographic findings. Mod Rheumatol 2013. In press.

8. Staa TPV, Geusens P, Bijlsma JWJ, Leufkens HGM, Cooper C: Clinical assessment of the long-term risk of fracture in patients with rheumatoid arthritis. Arthritis Rheum 2006, 54:3104-3112.

9. Kanis JA, McCloskey EV, Johansson H, Oden A, Ström O, Borgström F: Development and use of FRAX ${ }^{\circledR}$ in osteoporosis. Osteoporos Int 2010, 21:407-413

10. Nampei A, Hashimoto J, Koyanagi J, Ono T, Hashimoto $H$, Tsumaki $N_{\text {, }}$ Tomita T, Sugamoto K, Nishimoto N, Ochi T, Yoshikawa H: Characteristics of fracture and related factors in patients with rheumatoid arthritis. Mod Rheumatol 2008, 18:170-176.

11. Ochi K, Furuya T, Ikari K, Taniguchi A, Yamanaka H, Momohara S: Sites, frequencies, and causes of self-reported fractures in 9,720 rheumatoid 
arthritis patients: a large prospective observational cohort study in Japan. Arch Osteoporos 2013, 8:1-8.

12. Ejbjerg BJ, Vestergaard A, Jacobsen $\mathrm{S}$, Thomsen HS, ØStergaard M: The smallest detectable difference and sensitivity to change of magnetic resonance imaging and radiographic scoring of structural joint damage in rheumatoid arthritis finger, wrist, and toe joints: a comparison of the omeract rheumatoid arthritis magnetic resonance imaging score applied to different joint combinations and the sharp/van der heijde radiographic score. Arthritis Rheum 2005, 52:2300-2306.

13. Døhn UM, Ejbjerg BJ, Hasselquist M, Narvestad E, Moller J, Thomsen HS, Ostergaard M: Detection of bone erosions in rheumatoid arthritis wrist joints with magnetic resonance imaging, computed tomography and radiography. Arthritis Res Ther 2008, 10:R25.

14. Østergaard M, Pedersen SJ, Døhn UM: Imaging in rheumatoid arthritis - status and recent advances for magnetic resonance imaging, ultrasonography, computed tomography and conventional radiography. Best Pract Res Clin Rheumatol 2008, 22:1019-1044.

15. Alves C, Colin EM, van Oort WJ, Sluimer JP, Hazes JMW, Luime JJ: Periarticular osteoporosis: a useful feature in the diagnosis of early rheumatoid arthritis? Reliability and validity in a cross-sectional diagnostic study using dual-energy X-ray absorptiometry. Rheumatology 2011, 50:2257-2263.

16. Da Mota LMH, Laurindo IMM, dos Santos Neto LL, Lima FAC, Viana SL, Mendlovitz PS, Fernandes JL: Imaging diagnosis of early rheumatoid arthritis. Rev Bras Reumatol 2012, 52:757-766.

17. Døhn UM, Terslev L, Szkudlarek M, Hansen MS, Hetland ML, Hansen A Madsen OR, Hasselquist M, Møller J, Østergaard M: Detection, scoring and volume assessment of bone erosions by ultrasonography in rheumatoid arthritis: comparison with CT. Ann Rheum Dis 2013, 72:530-534

18. Atkinson SC, Cormia FE, Unrau SA: The diameter and growth phase of hair in relation to age. Br J Dermatol 1959, 71:309-311.

19. Møller Døhn U, Boonen A, Hetland ML, Hansen MS, Knudsen LS, Hansen A, Madsen OR, Hasselquist M, Møller JM, Østergaard M: Erosive progression is minimal, but erosion healing rare, in patients with rheumatoid arthritis treated with adalimumab. A 1 year investigator-initiated follow-up study using high-resolution computed tomography as the primary outcome measure. Ann Rheum Dis 2009, 68:1585-1590.

20. Stach CM, Bäuerle M, Englbrecht M, Kronke G, Engelke K, Manger B, Schett G: Periarticular bone structure in rheumatoid arthritis patients and healthy individuals assessed by high-resolution computed tomography. Arthritis Rheum 2010, 62:330-339.

21. Fouque-Aubert A, Boutroy S, Marotte H, Vilayphiou N, Bacchetta J, Miossec P, Delmas PD, Chapurlat RD: Assessment of hand bone loss in rheumatoid arthritis by high-resolution peripheral quantitative CT. Ann Rheum Dis 2010, 69:1671-1676.

22. Finzel S, Englbrecht M, Engelke K, Stach C, Schett G: A comparative study of periarticular bone lesions in rheumatoid arthritis and psoriatic arthritis. Ann Rheum Dis 2011, 70:122-127.

23. Finzel S, Ohrndorf S, Englbrecht M, Stach C, Messerschmidt J, Schett G, Backhaus M: A detailed comparative study of high-resolution ultrasound and micro-computed tomography for detection of arthritic bone erosions. Arthritis Rheum 2011, 63:1231-1236.

24. Schett G, Coates LC, Ash ZR, Finzel S, Conaghan PG: Structural damage in rheumatoid arthritis, psoriatic arthritis, and ankylosing spondylitis: traditional views, novel insights gained from TNF blockade, and concepts for the future. Arthritis Res Ther 2011 13(Suppl 1):S4.

25. Finzel S, Rech J, Schmidt S, Engelke K, Englbrecht M, Stach C, Schett G: Repair of bone erosions in rheumatoid arthritis treated with tumour necrosis factor inhibitors is based on bone apposition at the base of the erosion. Ann Rheum Dis 2011, 70:1587-1593.

26. Zhu TY, Griffith JF, Qin L, Hung WWY, Fong T-N, Kwok AW, Leung P-C, Li EK, Tam L-S: Bone density and microarchitecture: relationship between hand, peripheral, and axial skeletal sites assessed by HR-pQCT and DXA in rheumatoid arthritis. Calcif Tissue Int 2012, 91:343-355.

27. Srikhum W, Virayavanich W, Burghardt AJ, Yu A, Link TM, Imboden JB, Li X: Quantitative and semiquantitative bone erosion assessment on high-resolution peripheral quantitative computed tomography in rheumatoid arthritis. J Rheumatol 2013, 40:408-416.

28. Barnabe C, Szabo E, Martin L, Boyd SK, Barr SG: Quantification of small joint space width, periarticular bone microstructure and erosions using high-resolution peripheral quantitative computed tomography in rheumatoid arthritis. Clin Exp Rheumatol 2013, 31:243-250.

29. Zhu TY, Griffith JF, Qin L, Hung WWY, Fong T-N, Au S-K, Tang XL, Kwok AW Leung P-C, Li EK, Tam L-S: Structure and strength of the distal radius in female patients with rheumatoid arthritis: a case-control study. J Bone Miner Res Off J Am Soc Bone Miner Res 2013, 28:794-806.

30. Kleyer A, Finzel S, Rech J, Manger B, Krieter M, Faustini F, Araujo E, Hueber AJ, Harre U, Engelke K, Schett G: Bone loss before the clinical onset of rheumatoid arthritis in subjects with anticitrullinated protein antibodies. Ann Rheum Dis 2013. In press.

31. Barnabe C, Buie H, Kan M, Szabo E, Barr SG, Martin L, Boyd SK: Reproducible metacarpal joint space width measurements using 3D analysis of images acquired with high-resolution peripheral quantitative computed tomography. Med Eng Phys 2013. In press.

32. Aschenberg S, Finzel S, Schmidt S, Kraus S, Engelke K, Englbrecht M, Rech J, Schett G: Catabolic and anabolic periarticular bone changes in patients with rheumatoid arthritis: a computed tomography study on the role of age, disease duration and bone markers. Arthritis Res Ther 2013, 15:R62.

33. Barnabe C, Feehan L: High-resolution peripheral quantitative computed tomography imaging protocol for metacarpophalangeal joints in inflammatory arthritis: the SPECTRA collaboration. J Rheumato/ 2012, 39:1494-1495.

34. Ostergaard M, Møller Døhn U, Duer-Jensen A, Hetland ML, Hørslev-Petersen K, Stengaard-Pedersen K, Junker P, Pødenphant J, Ejbjerg B: Patterns of magnetic resonance imaging bone erosion in rheumatoid arthritis-which bones are most frequently involved and show the most change? J Rheumatol 2011 38:2014-2017.

35. De Rooy DPC, Kälvesten J, Huizinga TWJ, van der Helm-van Mil AHM: Loss of metacarpal bone density predicts RA development in recent-onset arthritis. Rheumatol Oxf Engl 2012, 51:1037-1041.

36. Moon S-J, Ahn IE, Kwok S-K, Park K-S, Min J-K, Park S-H, Kim H-Y, Ju JH: Periarticular osteoporosis is a prominent feature in early rheumatoid arthritis: estimation using shaft to periarticular bone mineral density ratio. J Korean Med Sci 2013, 28:287-294.

37. Buie HR, Campbell GM, Klinck RJ, MacNeil JA, Boyd SK: Automatic segmentation of cortical and trabecular compartments based on a dual threshold technique for in vivo micro-CT bone analysis. Bone 2007, 41:505-515.

38. Burghardt AJ, Buie HR, Laib A, Majumdar S, Boyd SK: Reproducibility of direct quantitative measures of cortical bone microarchitecture of the distal radius and tibia by HR-pQCT. Bone 2010, 47:519-528.

39. Burghardt AJ, Kazakia GJ, Ramachandran S, Link TM, Majumdar S: Age- and gender-related differences in the geometric properties and biomechanical significance of intracortical porosity in the distal radius and tibia. J Bone Miner Res Off J Am Soc Bone Miner Res 2010, 25:983-993.

40. Nishiyama KK, Macdonald HM, Buie HR, Hanley DA, Boyd SK: Postmenopausal women with osteopenia have higher cortical porosity and thinner cortices at the distal radius and tibia than women with normal aBMD: an in vivo HR-pQCT study. J Bone Miner Res Off J Am Soc Bone Miner Res 2010, 25:882-890.

41. Liu XS, Zhang XH, Sekhon KK, Adams MF, McMahon DJ, Bilezikian JP, Shane E, GUo XE: High-resolution peripheral quantitative computed tomography can assess microstructural and mechanical properties of human distal tibial bone. J Bone Miner Res Off J Am Soc Bone Miner Res 2010, 25:746-756.

42. Engelke K, Stampa B, Timm W, Dardzinski B, de Papp AE, Genant HK, Fuerst $\mathrm{T}$ : Short-term in vivo precision of BMD and parameters of trabecular architecture at the distal forearm and tibia. Osteoporos Int J Establ Result Coop Eur Found Osteoporos Natl Osteoporos Found USA 2012, 23:2151-2158.

43. Pauchard Y, Liphardt A-M, Macdonald HM, Hanley DA, Boyd SK: Quality control for bone quality parameters affected by subject motion in high-resolution peripheral quantitative computed tomography. Bone 2012, 50:1304-1310.

44. Flegal KM, Carroll MD, Kit BK, Ogden CL: Prevalence of obesity and trends in the distribution of body mass index among US adults, 1999-2010. JAMA J Am Med Assoc 2012, 307:491-497.

45. AAPM task group 23: AAPM report number 96: The measurement, reporting and management of radiation dose in CT. 2008. http://www.aapm.org/pubs/ reports/rpt_96.pdf. Accessed December 26, 2013.

46. Bonnick SL, Johnston CC Jr, Kleerekoper M, Lindsay R, Miller P, Sherwood L, Siris E: Importance of precision in bone density measurements. J Clin Densitom Off J Int Soc Clin Densitom 2001, 4:105-110. 
47. Pialat JB, Burghardt AJ, Sode M, Link TM, Majumdar S: Visual grading of motion induced image degradation in high resolution peripheral computed tomography: impact of image quality on measures of bone density and micro-architecture. Bone 2012, 50:111-118.

48. Laib A, Häuselmann HJ, Rüegsegger P: In vivo high resolution 3D-QCT of the human forearm. Technol Health Care Off J Eur Soc Eng Med 1998, 6:329-337.

49. Van Rietbergen B, Majumdar S, Pistoia W, Newitt DC, Kothari M, Laib A, Rüegsegger $P$ : Assessment of cancellous bone mechanical properties from micro-FE models based on micro-CT, pQCT and MR images. Technol Health Care Off J Eur Soc Eng Med 1998, 6:413-420.

50. Laib A, Rüegsegger P: Calibration of trabecular bone structure measurements of in vivo three-dimensional peripheral quantitative computed tomography with 28-microm-resolution microcomputed tomography. Bone 1999, 24:35-39.

51. Bonnick SL: Monitoring changes in bone density. Womens Health (Lond Engl) 2008, 4:89-97.

52. Sode M, Burghardt AJ, Pialat J-B, Link TM, Majumdar S: Quantitative characterization of subject motion in HR-pQCT images of the distal radius and tibia. Bone 2011, 48:1291-1297.

53. Cheung AM, Adachi JD, Hanley DA, Kendler DL, Davison KS, Josse R, Brown JP, Ste-Marie L-G, Kremer R, Erlandson MC, Dian L, Burghardt AJ, Boyd SK: High-resolution peripheral quantitative computed tomography for the assessment of bone strength and structure: a review by the Canadian bone strength working group. Curr Osteoporos Rep 2013, 11:136-146.

54. MacNeil JA, Boyd SK: Improved reproducibility of high-resolution peripheral quantitative computed tomography for measurement of bone quality. Med Eng Phys 2008, 30:792-799.

55. Landis JR, Koch GG: The measurement of observer agreement for categorical data. Biometrics 1977, 33:159-174.

56. Ito M, Nishida A, Koga A, Ikeda S, Shiraishi A, Uetani M, Hayashi K, Nakamura T: Contribution of trabecular and cortical components to the mechanical properties of bone and their regulating parameters. Bone 2002, 31:351-358.

57. Chevalley T, Bonjour JP, van Rietbergen B, Ferrari S, Rizzoli R: Fracture history of healthy premenopausal women is associated with a reduction of cortical microstructural components at the distal radius. Bone 2013, 55:377-383.

58. Bjørnerem Å, Bui QM, Ghasem-Zadeh A, Hopper JL, Zebaze R, Seeman E: Fracture risk and height: an association partly accounted for by cortical porosity of relatively thinner cortices. J Bone Miner Res 2013, 28(9):2017-2026.

59. Macdonald HM, Nishiyama KK, Kang J, Hanley DA, Boyd SK: Age-related patterns of trabecular and cortical bone loss differ between sexes and skeletal sites: a population-based HR-pQCT study. J Bone Miner Res Off J Am Soc Bone Miner Res 2011, 26:50-62.

60. Boutroy S, Bouxsein ML, Munoz F, Delmas PD: In vivo assessment of trabecular bone microarchitecture by high-resolution peripheral quantitative computed tomography. J Clin Endocrinol Metab 2005, 90:6508-6515.

61. Mueller TL, Stauber M, Kohler T, Eckstein F, Müller R, van Lenthe GH: Non-invasive bone competence analysis by high-resolution PQCT: an in vitro reproducibility study on structural and mechanical properties at the human radius. Bone $2009,44: 364-371$.

62. Bui M, Bjørnerem A, Ghasem-Zadeh A, Dite GS, Hopper JL, Seeman E: Architecture of cortical bone determines in part its remodelling and structural decay. Bone 2013, 55:353-358.

63. Buenzli PR, Thomas CDL, Clement JG, Pivonka P: Endocortical bone loss in osteoporosis: the role of bone surface availability. Biomed Eng: Int J Numer Methods; 2013.

64. Chen H, Zhou X, Fujita H, Onozuka M, Kubo K-Y: Age-related changes in trabecular and cortical bone microstructure. Int J Endocrinol 2013, 2013:213234.

65. Trombetti A, Stoermann C, Chevalley T, Van Rietbergen B, Herrmann FR, Martin P-Y, Rizzoli R: Alterations of bone microstructure and strength in end-stage renal failure. Osteoporos Int J Establ Result Coop Eur Found Osteoporos Natl Osteoporos Found USA 2013, 24:1721-1732.

66. Davis KA, Burghardt AJ, Link TM, Majumdar S: The effects of geometric and threshold definitions on cortical bone metrics assessed by in vivo high-resolution peripheral quantitative computed tomography. Calcif Tissue Int 2007, 81:364-371.

67. Tjong W, Kazakia GJ, Burghardt AJ, Majumdar S: The effect of voxel size on high-resolution peripheral computed tomography measurements of trabecular and cortical bone microstructure. Med Phys 2012, 39:1893-1903.
68. Kazakia GJ, Nirody JA, Bernstein G, Sode M, Burghardt AJ, Majumdar S: Age- and gender-related differences in cortical geometry and microstructure: improved sensitivity by regional analysis. Bone 2013, 52:623-631.

69. Zebaze R, Ghasem-Zadeh A, Mbala A, Seeman E: A new method of segmentation of compact-appearing, transitional and trabecular compartments and quantification of cortical porosity from high resolution peripheral quantitative computed tomographic images. Bone 2013, 54:8-20.

doi:10.1186/1471-2474-14-367

Cite this article as: Feehan et al: A customized protocol to assess bone quality in the metacarpal head, metacarpal shaft and distal radius: a high resolution peripheral quantitative computed tomography precision study. BMC Musculoskeletal Disorders 2013 14:367.

\section{Submit your next manuscript to BioMed Central and take full advantage of:}

- Convenient online submission

- Thorough peer review

- No space constraints or color figure charges

- Immediate publication on acceptance

- Inclusion in PubMed, CAS, Scopus and Google Scholar

- Research which is freely available for redistribution

Submit your manuscript at www.biomedcentral.com/submit
C) Biomed Central 